\title{
A new wine superpower? An analysis of the Chinese wine industry
}

\author{
Yuanbo Li and Isabel Bardají* \\ Departamento de Economía Agraria, Escuela y Gestión de Empresas, Escuela Técnica Superior de Ingeniería Agronómica, \\ Alimentaria y de Biosistemas, Universidad Politécnica de Madrid, Madrid, Spain
}

\begin{abstract}
China is one of the most attractive wine markets and a hopeful wine producer in the twenty-first century. Current studies of wine in China tend to focus on the wine market but seldom analyze the domestic wine industry, which contributes approximately $70 \%$ of the total wine consumed in the country. This paper reviews the wine history and the development of wine in China and analyses the current situation and perspectives of the Chinese wine industry, considering both traditional conditions such as wine production and wine policies, as well as new conditions such as e-commerce, climate change and domestic economy trend. We present a "SWOT" (strengths, weaknesses, opportunities and threats) analysis of the Chinese wine industry considering four sectors (producing, processing, selling and consuming) and we use a SWOT matrix analysis to identify possible improvement strategies. Finally, we propose strategies for the development of the Chinese wine industry at governmental level, industrial level and business level.
\end{abstract}

Keywords: China / wine / viticulture / SWOT analysis / agricultural policy

Résumé - Une nouvelle super-puissance viticole? Une analyse de l'industrie chinoise du vin. La Chine est l'un des marchés viticoles les plus attrayants et un producteur de vin prometteur pour le XXI siècle. Les études actuelles sur le vin en Chine se concentrent plutôt sur le marché du vin, mais analysent rarement l'industrie nationale du vin, qui contribue pourtant à environ $70 \%$ du vin consommé dans le pays. Cet article retrace l'histoire et le développement du vin en Chine et analyse la situation actuelle et les perspectives de l'industrie viticole chinoise. Il prend en compte le contexte classique concernant la production de vin et les politiques viticoles, tout en considérant aussi le contexte plus moderne du commerce électronique, du changement climatique et de l'économie chinoise. Nous présentons une analyse SWOT (forces, faiblesses, opportunités, menaces) de l'industrie viticole chinoise en considérant quatre secteurs (production, traitement, vente et consommation) et nous en déduisons des stratégies d'amélioration possibles grâce à une matrice SWOT. Enfin, nous proposons des stratégies pour le développement de l'industrie viticole chinoise, au niveau gouvernemental, au niveau industriel et au niveau commercial.

Mots clés : Chine / vin / viticulture / analyse SWOT / politiques agricoles

\section{Introduction}

In China, grape seeds have been found in ancient ruins by several archaeological excavations in Hunan, Henan and Zhejiang, with a historical span from 8000 B.C. to 3000 B.C. (Lv and Zhang, 2013; Wang et al., 2016). During the Han Dynasty (206 B.C.-220 A.D.), Vitis vinifera (common grape vine) was introduced from Central Asia (Wang and Huang, 2009). In many dynasties of China, it is easy to find historical references of wine making and wine consumption (Jenster and Cheng, 2008).

\footnotetext{
*Corresponding author: isabel.bardaji@upm.es
}

In 1892, Zhang Bishi (1841-1916) established the first Chinese wine company, Changyu, in the coastal city of Yantai in Shandong, which marked the beginning of the modern Chinese wine industry (Mitry et al., 2009). The dramatic growth of the Chinese economy over the past three decades has supported the development of the domestic wine industry. Since 2001, when China joined the World Trade Organization (WTO), a large number of foreign wines have entered China, bringing competition, new technology and management experience. However, emerging factors such as e-commerce, wine tourism, the slowdown of the Chinese economic growth rate and the "anticorruption" campaign, present both challenges and opportunities for the Chinese wine industry. There are already many researches 
into the Chinese wine market, such as consumer preference and wine drinking behavior, but less about wine production in China, which are needed (Yu et al., 2009; Somogyi et al., 2011; Capitello et al., 2017). The main purpose of this research is to analyze the current situation and the perspectives of wine industry in China, considering both traditional and new conditions and with a goal to provide strategies.

\section{Methods}

SWOT represents strengths, weaknesses, opportunities and threats. SWOT analysis considers both the current strengths and weaknesses and the future opportunities and threats (Corsi et al., 2013). SWOT analysis has been a useful tool for analyzing complex strategic situations by reducing the information quantity needed to achieve a better decision; SWOT matrix is produced to generate strategies based on internal and external factors of SWOT analysis (Helms and Nixon, 2010). SWOT analysis and SWOT matrix have been applied in many scientific fields including studies of wine industry, wine tourism and wine market in several countries (Carlsen and Dowling, 2001; Terblanche et al., 2008; Čačić et al., 2010; Corsi et al., 2013).

First, we analyze the Chinese wine industry under both traditional and new conditions. Secondary data are collected from government reports, business reports, online resources and research papers. Second, we apply SWOT analysis to explore the internal and external factors that will determine the development of the wine industry in China. Third, we classify SWOT factors in four sectors (producing, processing, selling and consuming) of wine industry. We then establish a SWOT matrix according to the four sectors to achieve strategies for the further development of China's wine industry. Finally, we generalize and classify strategies obtained at governmental level, industrial level and business level.

\section{Results}

\subsection{Wine production}

Wine regions are widely distributed in China from the east coastal areas to the west desert areas where distinct geographical and climatic conditions exist (Fig. 1). The domestic wine industry has developed significantly since the "reform and opening up" policy in 1978 (Fig. 1). In the period of 1980-1990, the Chinese vineyard areas developed very slowly, around 30000 ha with a small production of grape below 900000 tons (Li et al., 2009). During this period, the "half-juice wine" which mixed grape juice with water, sugar and other fruit juice, was the main wine product in the market, and several problems of food quality existed. Between 1991 and 2000, the Chinese wine industry had a period of regulation and adjustment. In 1994, the production of "half-juice wine" containing less than $50 \%$ grape juice was permanently prohibited. In 2004, the production of all kinds of "half-juice wine" was totally forbidden, which encouraged the production of fine wines containing $100 \%$ of grape juice. Since 2000 , the regulation of "half-juice wine", the fast growing economy and increasing market demand, the encouragement of government, the development of society, the advancement of technology and management, and the competition by foreign competitors
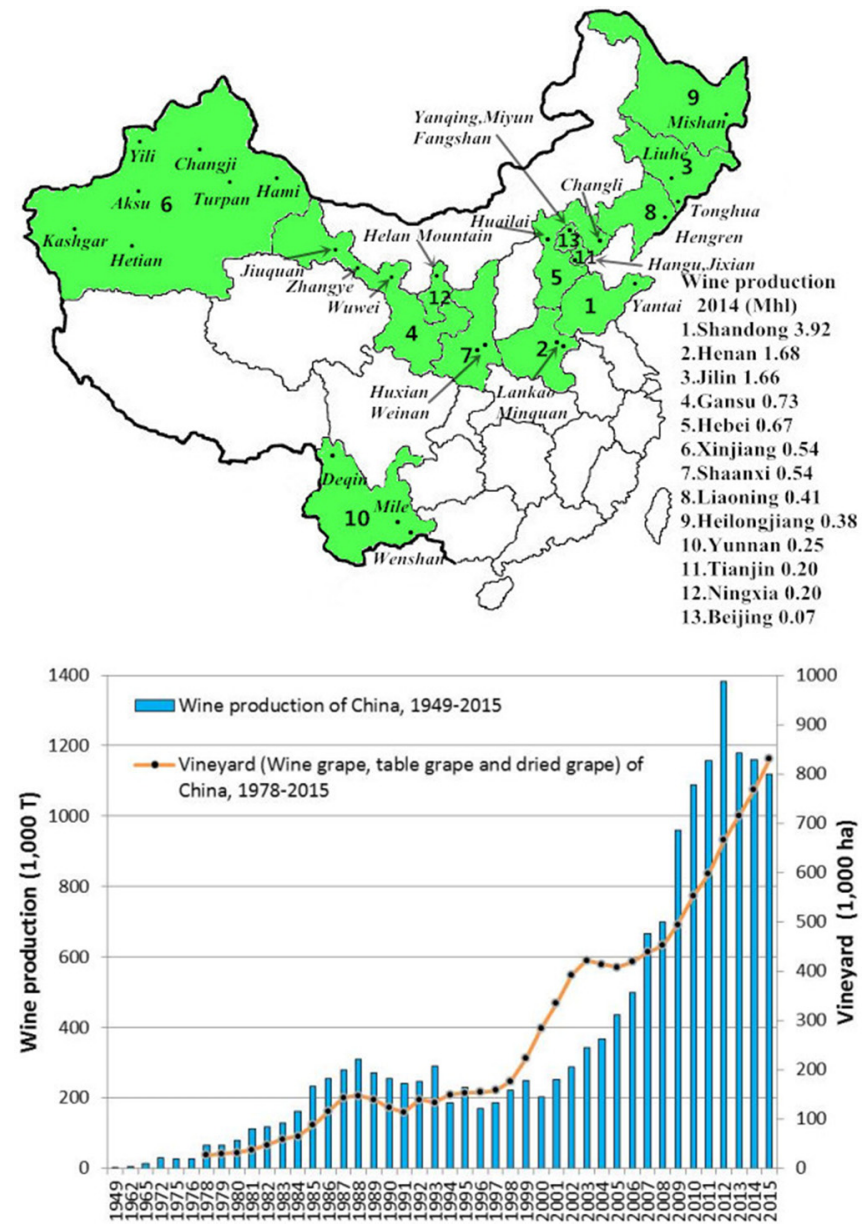

Fig. 1. Main wine regions and wine production in China.

Source: Data of wine production of China: Yearbook of China Alcoholic Drinks Industry (2001), China Sugar \& Liquor Yearbook (2003-2011), ASKCI (2016), OIV (2016); data of wine production by region: CHYXX, 2015; data of vineyard: National Bureau of Statistics of China (2016).

Fig. 1. Principales régions viticoles et production viticole en Chine.

after China's WTO accession, facilitated the growth of domestic wine industry, which could be observed during the period from 2004 to 2007 (Fig. 1).

As shown in Figure 1, the domestic wine production increased from $0.78 \mathrm{Mhl}$ (million hectoliters) to $11.50 \mathrm{Mhl}$ and the total vineyard area scaled up from 31600 ha to 830000 ha from 1980 to 2015. Even though tremendous expansion of vineyard has been achieved, only approximately $10 \%$ of the total vineyards are for wine grape (the rest being for table and dried grape); Cabernet Sauvignon is the most widely planted wine grape variety ( $\mathrm{Li}$ et al., 2009; $\mathrm{Li}, 2016$ ). China had the world's second largest vineyard area $(830000 \mathrm{ha}$, for table grape, wine grape and dried grape) and the eighth largest global wine grape production (1.48 million tons, $12 \%$ of the total grape production) in 2015 (OIV Statistical Report on World Vitiviniculture, 2016). In 2015 China was the eighth largest world wine producer with a volume of $11.50 \mathrm{Mhl}$ as in Figure 2. Currently, more than $80 \%$ of domestic wine production is dry wine, among which $90 \%$ is dry red wine, followed by sweet wine with $10 \%$ (CNFOODNET, 2017). 


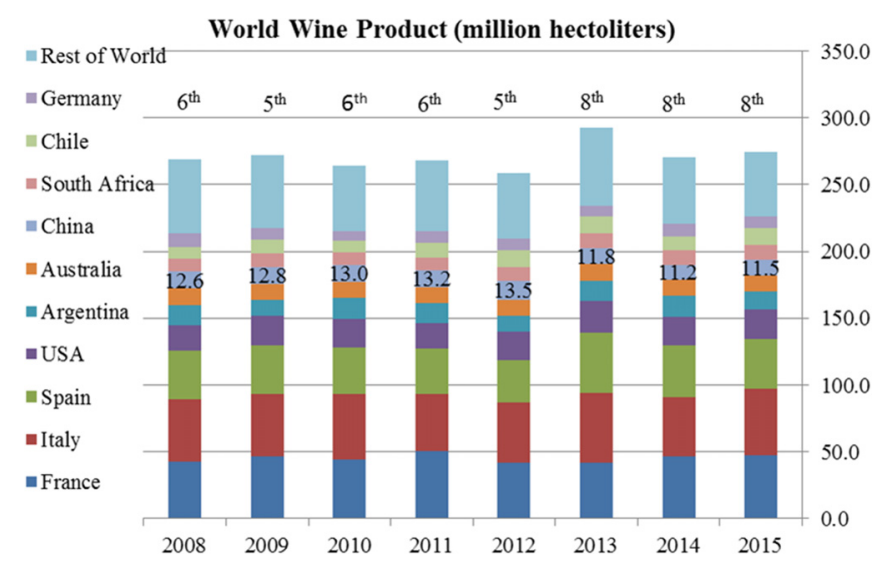

Fig. 2. World wine product.

Source: OIV (2016).

Fig. 2. Production mondiale du vin.

In spite of the significant development of the Chinese wine industry, there are many challenges. Problems such as low yield and poor quality, homogeneity of products, and inconsistent standards, are hindering the development of Chinese vineries (Wang et al., 2010). The development of wine cluster needs several necessary supports such as a favorable development environment, good cooperation among enterprises and adequate talent resources (Ma and Qiao, 2009). Improved regulations and legislations are necessary to solve the existing confusion and irregularity in the whole process from wine grape planting to wine making (Li et al., 2009).

In addition, global climate change is a common challenge for all countries and expected to have tremendous effects on agriculture (Banna et al., 2016; Lacombe et al., 2017). Changing climatic conditions that are likely to be highly variable will have significant impact on viticulture and wine production (Jones et al., 2005). Hence, there is a great need of climate adaptation strategies for wine industry in China to face challenges and opportunities ( $\mathrm{Li}$ and Bardají, 2017).

\subsection{Government support}

The "12th Five-Year (2011-2015) Plan" for the Chinese wine industry, released in 2012 by the Ministry of Industry and Information Technology of China, summaries five achievements of the Chinese wine industry during the "11th Five-Year (2006-2010)" period, such as enlargement of wine industry and wine enterprises, wine industry development in distinct regions, improved quality of raw materials, trend of branding and product differentiation and improvement in technology and innovation. However, there are five existing problems to be solved, such as a lack of suitable plan for development, a lack of raw material supplying bases, an urgent need of high technology and innovation, low quality and wine fraud, and a lack of wine culture. This plan also highlights the importance of government guidance and support to the Chinese wine industry especially in the improvement of wine producing regions, the adjustment of industrial structure, the development of science and technology, the assurance of product quality and the combination of wine culture and Chinese wine brands in the future development.

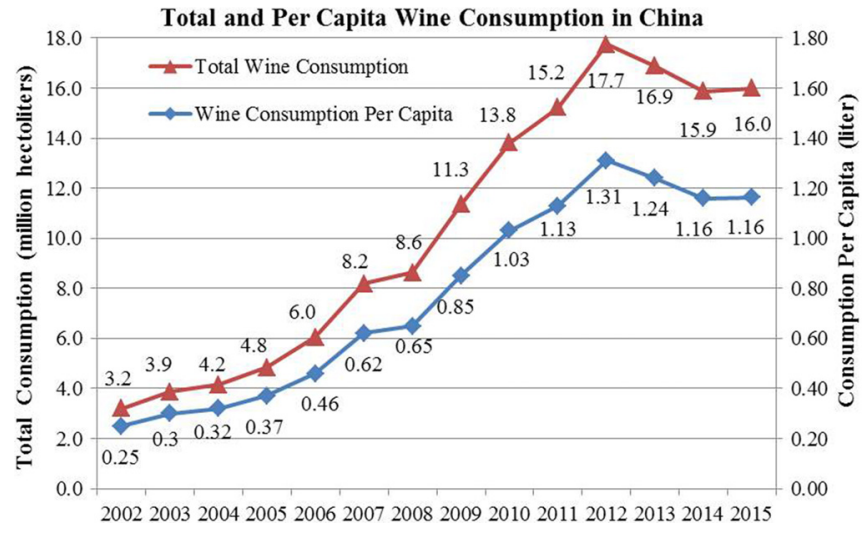

Fig. 3. Wine consumption in China.

Source: Data of wine consumption: ASKCI (2016), OIV (2016); data of population: National Bureau of Statistics of China (2016); and calculated by author.

Fig. 3. Consommation de vin en Chine.

Several provinces have promulgated regional policies for local wine industries such as the "Regulation on the protection of Eastern Foot of Helan Mountain Wine Region" and the "Ningxia winery classification system" of Ningxia, the "Development plan for the wine industry (2015-2025)" of Xinjiang, the "Suggestions for the promotion of the development of food industry" of Hebei, and the "Wine industry development plan (2010 2020)" of Gansu. However, compared with other main wine producing countries, which have a complete legal system, China still has a long way to go.

Institutionally, the need to develop the Chinese domestic wine industry urges the expansion of a high-level education on wine. Until 2015, China had above 16 universities offering the major "Viticulture and Enology Engineering" in the bachelor education, such as the Northwest Agriculture and Forest University and the China Agricultural University which are among top universities of China, and above 15 institutes for grape and wine research in several regions. In the meantime, a growing interest of professional wine knowledge and culture has been observed, especially among middle class in big cities. China has been one of the most important markets for the Wine \& Spirit Education Trust (WSET) Organization that specializes in wine education (WSET, 2015).

\subsection{Wine demand}

In 2013, China passed France as the world's largest consuming country for red wine (Willsher, 2014). China was the fifth largest global market for all kinds of wine in 2015 with $16 \mathrm{Mhl}(\mathrm{OIV}, 2016)$. There was a rising trend in both the total alcohol consumption and the per capita wine consumption in China (Fig. 3). Even though the total wine consumption is huge, the per capita wine consumption is still small, with only 1.16 liters in 2014 (Fig. 3).

However, the slowdown of the economic growth rate or the "new normality" of the Chinese economy affects both the wine consumption and production. At the same time, the "anticorruption" campaign, to some extent, leads to a decrease in 
wine selling. From 2012 to 2013, the wine consumption dropped from $17.48 \mathrm{Mhl}$ to $16.82 \mathrm{Mhl}$ and the wine consumption further decreased to $15.80 \mathrm{Mhl}$ in 2014 . For wines from Bordeaux region, the sales volume decreased by $9 \%$ and the sales value decreased by $17 \%$ in 2014 (Eads, 2015).

In China for main wine distribution channels, shopping malls and supermarkets have a 30 percent market share, restaurants and hotels have an 18 percent market share, wine stores, e-commerce and group-buying in total have a 25 percent market share (CNFOODNET, 2017). E-commerce, where $72 \%$ of wines sold are imported wines is fast growing and several wine suppliers have participated in e-commerce, which offers a new market channel for wine companies and a new shopping platform for wine consumers (CNFOODNET, 2017). As a response to the interest of wine and the desire of leisure, wine tourism has developed in China (Qiu et al., 2013). Many local governments intend to develop the wine tourism to support the local wine industries and to attract investment like the plan of "Helan Mountain Grape Culture Corridor" by Ningxia Government.

\subsection{Wine trade}

Chinese wine enterprises are experiencing a market share decrease for the competition of imported foreign wines, of which the majorities are bottled wines. Recently, some Chinese investments even flow into foreign wine industry like acquisition of chateaux in France and vineyards in Australia and sell wines back to China (Louise and Michael, 2015).

Since the entry into WTO in 2001, the imported wine tariff fell from $65 \%$ to $14 \%$ (bottled wine) and $20 \%$ (bulk wine). Foreign wines began to enter the Chinese market at a fast pace (Fig. 4). For the Chinese market, currently approximately $30 \%$ of the wines consumed are imported wines and this number may increase (CNFOODNET, 2017). France, Australia, Chile, Spain, Italia are main wine exporters to China (Fig. 5). French wines occupy the largest sale volume and the largest sale value of bottled wine in China. For Chinese customers, France culture and food bring a good image to French wines and contribute heavily to the sale success (Yu et al., 2009). New Zealand and Chile have the zero-tariff to enter the Chinese market since 2012 and 2015 respectively whereas Australia has reduction of tariff year by year since 2016 and will eventually get zero-tariff in 2019. With the lower-priced wines such as Chilean and Spanish wines, the Chinese wine will face a big challenge. In addition, an obvious increase in both the import volume and the import value has been observed in 2015 compared to 2014 (Fig. 4). There are mainly three reasons for this import increase, which are more consumption of low-end wines, import tariff adjustment for wines from New Zealand and Chile, and wine stock by suppliers after the "hard period" of sale. Meanwhile, the recent decline in the wine import price (Fig. 4) indicates adjustment of market, vigorous competitiveness and maturity of Chinese consumers, who value wines not only from higher price.

\subsection{SWOT analysis of the Chinese wine industry}

Based on previous work and SWOT theory, we identified six internal factors for Strengths, nine internal factors for
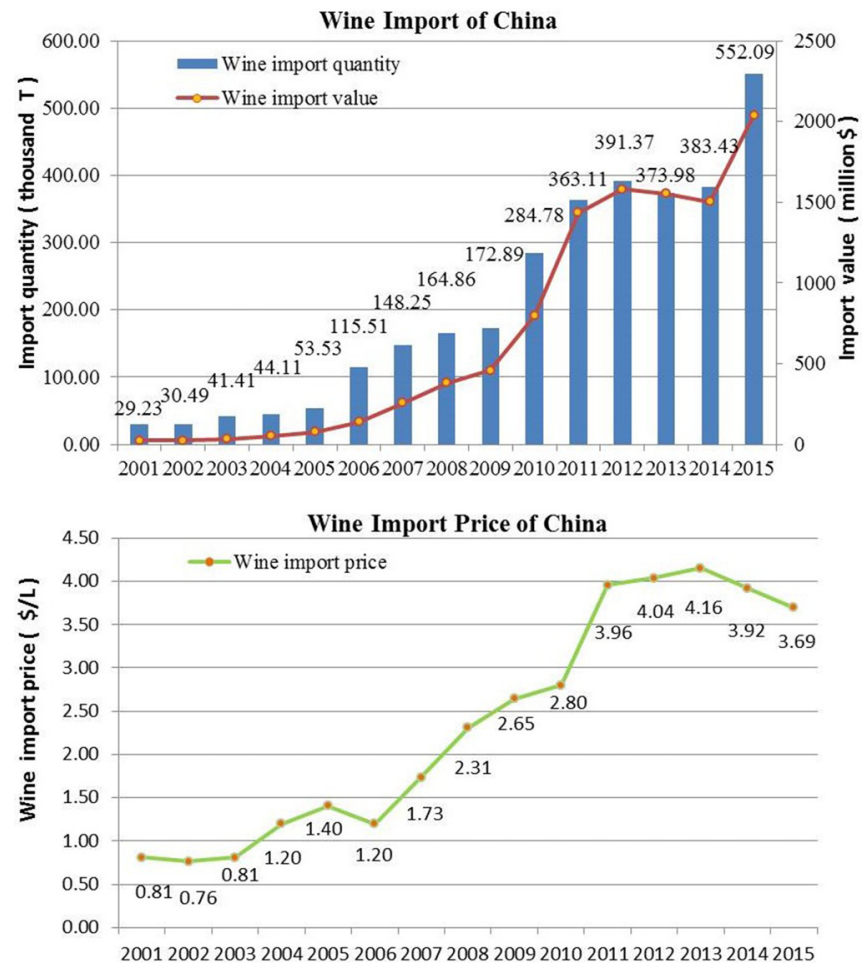

Fig. 4. Wine import of China. Source: UN Comtrade (2016).

Fig. 4. Importation de vin en Chine.

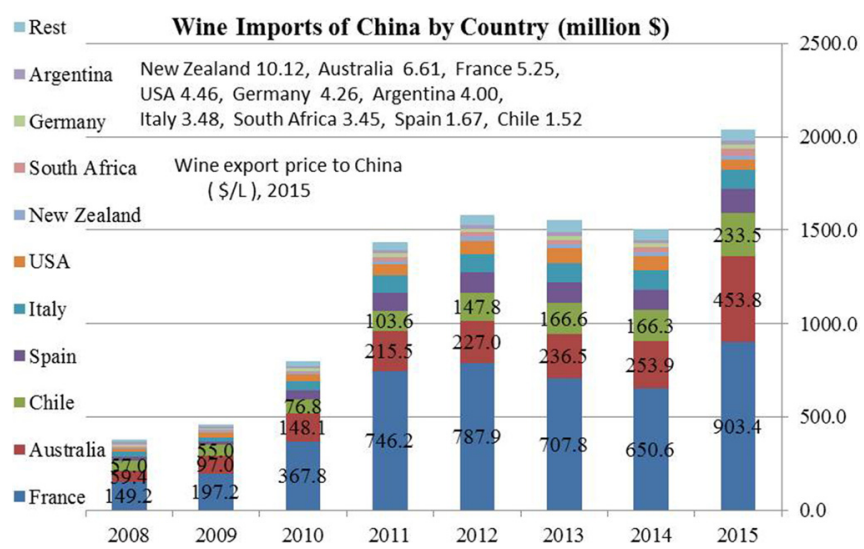

Fig. 5. Wine import of China by country. Source: UN Comtrade (2016).

Fig. 5. Importation de vin de Chine par pays.

Weaknesses, nine external factors for Opportunities and seven external factors for threats in Table 1.

Then, to understand their roles and connections in wine industry and to better achieve SWOT strategies, we classified these 31 factors in four interactive sectors connected by dotted lines - Grape Producing, Wine Processing, Wine Selling and Wine Consuming of wine industry - in Figure 6. Each factor is connected with one or more sectors with solid lines.

Next, we built a SWOT matrix in Figure 7, based on factors classified in four sectors of wine industry. Internal factors (strengths and weaknesses) are listed horizontally and 
Table 1. Strengths, weaknesses, opportunities and threats of the Chinese wine industry.

Source: own elaboration.

Tableau 1. Points forts, faiblesses, opportunités et menaces de l'industrie viticole chinoise.

\begin{tabular}{llll}
\hline Strengths & Weaknesses & Opportunities & Threats \\
\hline S1. Broad territory for vineyards. & $\begin{array}{l}\text { W1. Lack of experience, } \\
\text { technology, infrastructure, } \\
\text { and professional talents. }\end{array}$ & $\begin{array}{l}\text { O1. Large population size and } \\
\text { huge market demand. }\end{array}$ & $\begin{array}{l}\text { T1. Competition from foreign wines } \\
\text { (such as high technology, mature } \\
\text { management system, zero tariff). }\end{array}$
\end{tabular}

S2. High potential for wine grape planting and wine making due to diverse climate, geographical, environmental and ecological conditions.

S3. Native varieties of wine grape in China.

S4. Current grape planting and wine making regions are widely distributed with diverse industrial structures and clusters; local wine industries have easier access to markets.

S5. Sufficient labor force in China especially in the rural area.

S6. Advantages of domestic wines such as the price advantage especially for the low-end consumers and the familiar image in local market.
W2. Lack of wine culture and heritage.

W3. Lack of a complete legal system of wine.

W4. Low quality and yield, distinct standards, homogeneity of products.

W5. Wine is not the traditional alcohol drink in China.

W6. Lack of some international well-known brands.

\section{W7. Regional uneven development of wine industry.}

W8. Non-oriented and irrational investment in wine industry.

W9. Lack of highly developed wine clusters.
O2. Increasing economy (perincome) and improved living standard.

\section{O3. Government support} (political, educational, technical, financial etc.).

O4. Good image of wine such as the health benefits of wine and red is a "lucky" color in China.

O5. Dining and gift giving custom of Chinese.

O6. More interest on wine and wine culture; increasing wine knowledge of Chinese customers.

O7. Development of the wine industries such as wine labor force and management. tourism, grape picking, wine tasting, exhibition.

O8. E-commerce.
T2. Competition from other alcohol drinks.

T3. Slowdown of the China's economy.

T4. Sale falls for the "anticorruption" campaign.

T5. Mistrust of consumers towards the safety and quality of Chinese food products.

T6. Negative effects of climate change. change.

external factors (opportunities and threats) are listed vertically. If one strategy can be developed, the grid corresponding to such a matrix is painted with one certain color (Yellow for SO; Green for ST; Blue for WO and Red for WT).

Finally, we generalized and classified the SWOT matrix strategies obtained at governmental level, industrial level and business level, for the further development of China's wine industry. For one specific strategy, its general strategy type ( $\mathrm{SO}, \mathrm{ST}, \mathrm{WO}$ and WT) is indicated in parentheses.

\section{Strategies for the development of the Chinese wine industry}

\subsection{Governmental level}

Unlike some wine producing countries where wine industry is highly supported by agricultural subsidies, wine industry in China belongs to light industry and is charged by the China National Light Industry Council while the Ministry of Agriculture of China administrates viticulture. Such 


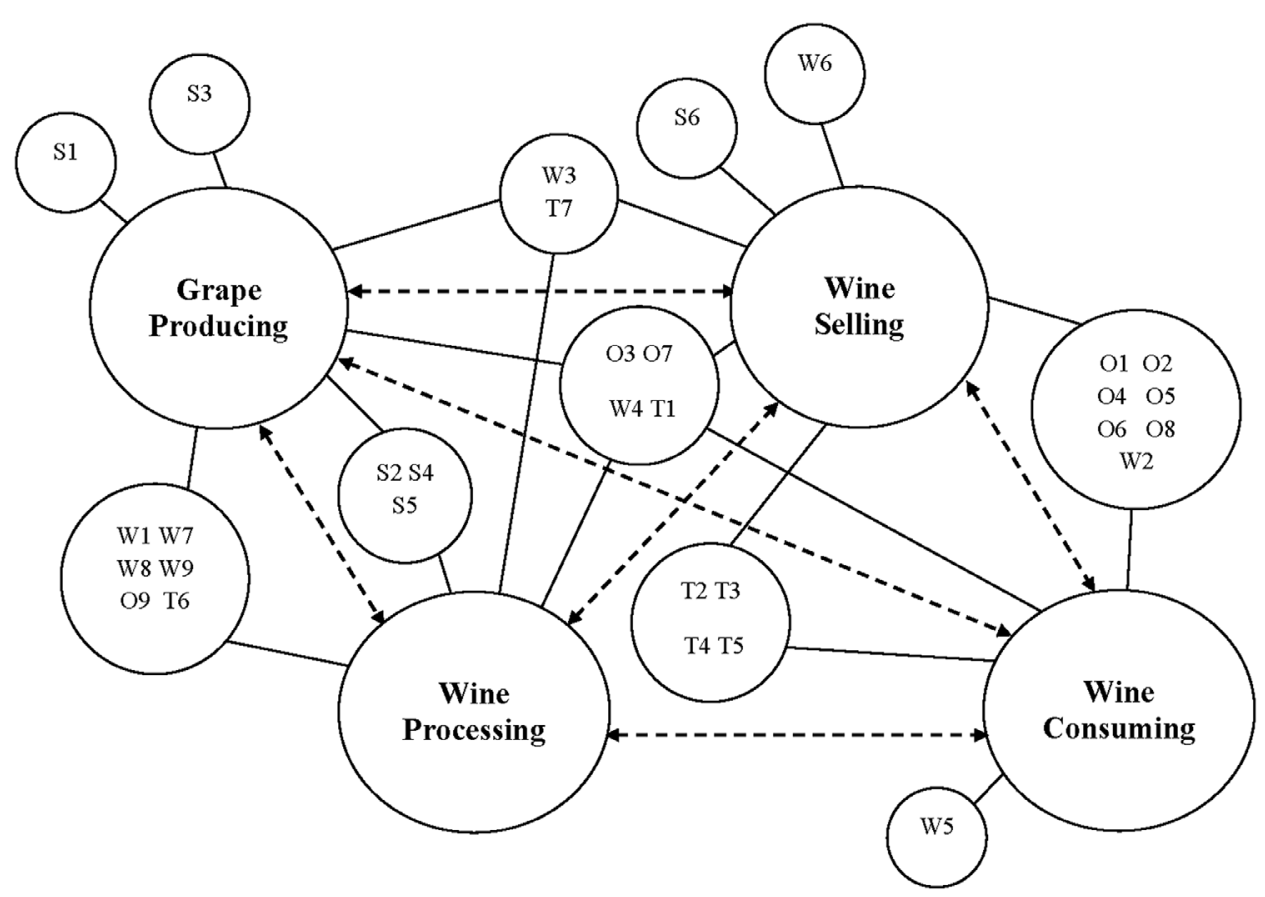

Fig. 6. Network of SWOT factors of the Chinese wine industry. Source: own elaboration.

Fig. 6. Réseau des facteurs SWOT de l'industrie viticole chinoise.

management of wine industry leads to the tax burdens of wine enterprises and the difficulty to collect accurate and coherent data of wine grape planting and wine making. In addition, lands in China are state-owned and technically owned by rural communities of farmers. Hence, wineries have to hire farmers of communities that technically own lands to cultivate wine grapes or rent lands from such communities. Obviously, this kind of land ownership may lead to a difficulty of vineyard management and quality guarantee of wine grapes and less competitiveness compared to foreign wine industries. At the present stage, the Chinese wine industry is in the early phase of industrialization with a comparatively weak industrial condition. The Chinese government could support the domestic wine industry at legal level, financial level, technical level, educational level, institutional level and cooperative level (SO and $\mathrm{WO}$ ).

A national complete wine law system targeting all the phases of wine industry is highly needed. Meanwhile regional efforts to regulate the local wine industry should be encouraged in different wine regions ( $\mathrm{SO}, \mathrm{WO}$ and $\mathrm{WT}$ ).

A national wine classification regulation considering China's national conditions and learning from countries which already have wine classification system like France from "Old World" and Chile from "New World" should be promulgated. Beside this, in wine regions, local wine and winery classification system could be promulgated. This approach may provide new references for both traditional wine players and emerging wine countries (SO, WO and WT).

Wine product quality standards, wine quality control and inspection systems should be further improved while a wine quality and safety traceability system should be established to regulate wine products and ensure wine quality (SO, WO and WT).
International exchange and cooperation are beneficial for the Chinese wine industry in which advanced technology and management experience could be learned and further international cooperation could be made. The Yantai (Shandong) and the Ningxia Hui autonomous region have been observers of the International Organization of Vine and Wine (OIV). These are one hope that China will soon join the OIV so that Chinese wine industry can learn from international standards and benefit from advanced technologies and experiences. At the same time, China can share its own ideas in the development of international wine and grape standards and trade rules through this international platform (WO and WT).

Government leading mitigation and adaptation actions are indispensable response to challenges and opportunities by climate change (SO, ST, WO and WT).

There is a need to popularize wine knowledge and spread wine culture by wine education and wine training to guide Chinese customers for a rational and healthy consuming behavior in which domestic wine associations, wine institutes and wine academies can cooperate with the government (WO and WT).

Wine historical remains should be protected and wine culture and history with Chinese characteristics could be further excavated (WO and WT).

\subsection{Industrial level}

The Chinese wine industry can fully take advantage of the broad and suitable Chinese territories for wine grape planting with improved technologies and management (SO and ST).

Selection of wine grape varieties and planting methods should be taken into consideration according to local climatic 


\begin{tabular}{|c|c|c|c|c|c|c|c|c|c|c|c|}
\hline \multicolumn{7}{|c|}{ SWOT matrix for the wine industry of China } \\
\hline Prod & S1 & S2 & S3 & S4 & S5 & W1 & W3 & W4 & W7 & W8 & W9 \\
\hline O3 & & & & & & & & & & & \\
\hline O7 & & & & & & & & & & & \\
\hline O9 & & & & & & & & & & & \\
\hline T1 & & & & & & & & & & & \\
\hline T6 & & & & & & & & & & \\
\hline 77 & & & & & & & & & & & \\
\hline Proc & S2 & S4 & S5 & W1 & W3 & W4 & W7 & W8 & W9 & & \\
\hline O3 & & & & & & & & & & & \\
\hline O7 & & & & & & & & & & & \\
\hline O9 & & & & & & & & & & \\
\hline T1 & & & & & & & & & & & \\
\hline T6 & & & & & & & & & & \\
\hline T7 & & & & & & & & & & \\
\hline Sell & S6 & W2 & W3 & W4 & W6 & Cons & W2 & W4 & W5 & & \\
\hline O1 & & & & & & O1 & & & & & \\
\hline O2 & & & & & & O2 & & & & & \\
\hline O3 & & & & & & O3 & & & & & \\
\hline O4 & & & & & & O4 & & & & & \\
\hline O5 & & & & & & O5 & & & & & \\
\hline O6 & & & & & & O6 & & & & & \\
\hline O7 & & & & & & O7 & & & & & \\
\hline O8 & & & & & O8 & & & & & \\
\hline T1 & & & & & T1 & & & & & \\
\hline T2 & & & & & & T2 & & & & & \\
\hline T3 & & & & & & T3 & & & & & \\
\hline T4 & & & & & & T4 & & & & & \\
\hline T5 & & & & & T5 & & & & & \\
\hline 77 & & & & & & & & & & \\
\hline & Legend & & SO Strategy & ST Strategy & WO Strategy & WT Strategy \\
\hline Prod: Grape Producing, Proc: Wine Processing, Sell: Wine Selling, Cons: Wine Consuming \\
\hline
\end{tabular}

Fig. 7. SWOT matrix of the Chinese wine industry. Source: own elaboration.

Fig. 7. Matrice SWOT de l'industrie viticole chinoise.

and geographical conditions. The value of domestic grape varieties such as the Vitis amurensis (hill grape) in the Northeast China and the Vitis quinquangularis Rehd in Guangxi can be used. In addition, a diverse and sustainable way for development is crucial (SO, ST, WO, and WT).

Advisable plan of industry, upgrade of industrial structure and industrial innovation are indispensable for the development of wine clusters. The advantage of abundant natural resources in the west and the advantage of well-known domestic wine brands and sufficient capital in the east of China can be combined (SO, ST, WO and WT).

Wine related industries such as wine tasting education, grape picking entertainment, wine tourism and wine exhibition can lead to a diverse development of wine industry and create vast job opportunities ( $\mathrm{SO}$ and $\mathrm{WO}$ ).

The appearance of wine chateau development especially in Shandong and Ningxia is the focus of Chinese wine enterprises towards domestic high quality wines and luxury brands. In addition, the appearance of chateau, which combines quality wines with culture and history, can enhance the quality of Chinese wines and motivate domestic customers. Hence, there is a great need to regulate and classify the rising Chinese chateau wines by specific regulations (WO and WT).

\subsection{Business level}

Quality and safety assurance, product differentiation and product innovation can contribute to the improvement of domestic wines and enhance the confidence of Chinese customers towards Chinese wines, which face a fierce competition from foreign wines (WO and WT).

Wine products should be adapted to conform to consuming tradition, cultural specificity, market trends, and a declining rate of economic growth. In the vast area of small Chinese cities and countryside, there is a major potential demand for lower-priced wines (SO, ST, WO and WT). 
Wine is not only an alcoholic drink but also a representative of culture and history. Hence, it is reasonable to endow domestic wines with cultural symbolism. Domestic vintners should highlight the Chinese culture and refer to the Chinese traditions (WO and WT).

The lack of wine knowledge and information hinders wine consumption of domestic customers. It is necessary to broadcast wine knowledge and guide customers' wine drinking behaviors. A new marketing network, which combines traditional market channels and e-commerce, is beneficial for market expansion and market competitiveness (SO, WO and WT).

\section{Conclusions}

The Chinese wine industry has benefited from excellent natural condition, growing domestic economy, strong government support, and advanced technologies and management. But there is a great need to make further improvements in several aspects such as the establishment of a complete wine law system and a wine classification regulation. While opportunities such as e-commerce and increasing wine knowledge levels of customers can benefit the wine industry of China, coming challenges such as market volatility and climate change cannot be ignored. For the development of Chinese wine industry in the future, certain strategies proposed by this study could be taken into consideration at governmental level, industrial level and business level.

Our analysis could not cover all the possible aspects of the Chinese wine industry, which is huge and fast developing. Hence, more comprehensive and in-depth work is required in the future.

Acknowledgements. The authors would like to acknowledge the financial support from the China Scholarship Council (CSC) and the research support from the Research Center for the Management of Agricultural and Environmental Risks (CEIGRAM) of the Universidad Politécnica de Madrid. An early version of this work was published as the No.198 Working Paper in the American Association of Wine Economists (AAWE). We deeply acknowledge the helpful comments and suggestions of anonymous reviewers.

\section{References}

ASKCI. 2016. 中商情报网 (in Chinese). Available at http://www. askci.com/ [2016/1/10].

Banna H, Afroz R, Masud MM, Rana MS, Koh E HY, Ahmad R. 2016. Financing an efficient adaptation programme to climate change: a contingent valuation method tested in Malaysia. Cah Agric 25(2): 1-8.

Čačić J, Kljusurić JG, Karpati L, Čačić D. 2010. Collective wine export promotion in transitional countries: the case of Croatia. $J$ Food Prod Market 16(3): 262-277.

Capitello R, Charters S, Menival D, Yuan JX. 2017. The wine value chain in China: consumers, marketing, and the wider world. Oxford: Chandos Publishing, $3 \mathrm{p}$.

Carlsen J, Dowling R. 2001. Regional wine tourism: a plan of development for Western Australia. Tourism Recreat Res 26(2): $45-52$.
China Sugar \& Liquor Yearbook (2003-2011) (In Chinese). Publication of China National Association for Liquor and Spirits Circulation.

CHYXX. 2015. Chinese Industry Information Network (In Chinese). Available at http://www.chyxx.com/ [2015/12/10].

CNFOODNET. 2017. China Food Network (In Chinese). Available at http://www.cnfoodnet.com/content-65-17736-1.html [2017/10/ 14].

Corsi AM, Marinelli N, Sottini VA. 2013. Italian wine and Asia: policy scenarios and competitive dynamics. Brit Food J 115(3): 342-364.

Eads L. 2015. Bordeaux takes hit over China crackdown. The drinks business. Available from https:/www.thedrinksbusiness.com/ 2015/03/bordeaux-takes-hit-over-china-crackdown/ [2015/11/20].

Helms MM, Nixon J. 2010. Exploring SWOT analysis - where are we now? A review of academic research from the last decade. $J$ Strat Manage 3(3): 215-251.

International Organization of Vine and Wine (OIV). 2016. Available at http://www.oiv.int/es/ [2016/3/1].

Jenster P, Cheng YT. 2008. Dragon wine: developments in the Chinese wine industry. Int $J$ Wine Business Res 20(3): 244-259.

Jones GV, White MA, Cooper OR, Storchmann K. 2005. Climate change and global wine quality. Clim Change 73(3): 319-343.

Lacombe G, Polthanee A, Trébuil G. 2017. Long-term change in rainfall distribution in Northeast Thailand: will cropping systems be able to adapt? Cah Agric 26(2): 1-10.

Li DM. 2016. A guide to Chinese wine regions. Decantar China. Available from https://www.decanterchina.com/en/col umns/demeis-view-wine-communication-from-a-chinese-wine maker/a-guide-to-chinese-wine-regions [2016/2/14].

Li H, Li JG, Yang HC. 2009. Review of grape and wine industry development in recent 30 years of China's Reforming and Opening-up (In Chinese). Mod Food Sci Technol 25(4): 341-347.

Li YB, Bardají I. 2017. Adapting the wine industry in China to climate change: challenges and opportunities. OENO One 51(2): 71-89.

Louise C, Michael T. 2015. Chinese FDI in the French and Australian wine industries: liabilities of foreignness and country of origin effects. Front Bus Res China 9(3): 443-480.

Lv QF, Zhang B. 2013. History of native grape and wine in ancient China (In Chinese). J Northwest A\&F Univer (Social Science Edition) 13(3): 157-162.

Ma XR, Qiao J. 2009. Cluster development of wine industry in China: status, measurement and evaluation (in Chinese). Technol Econ 28 (5): 41-46.

Mitry DJ, Smith DE, Jenster PV. 2009. China's role in global competition in the wine Industry: a new contestant and future trends. Int J Wine Res 2009(1): 19-25.

National Bureau of Statistics of China. 2016. (In Chinese). Available at http://www.stats.gov.cn/ [2016/3/5].

OIV Statistical Report on World Vitiviniculture, 2016. International Organization of Vine and Wine (OIV). 2016.

Qiu HZ, Yuan J, Ye BH, Hung K. 2013. Wine tourism phenomena in China: an emerging market. Int $J$ Contemp Hosp $M$ 25(7): $1115-1134$.

Somogyi S, Li E, Johnson T, Bruwer J, Bastian S. 2011. The underlying motivations of Chinese wine consumer behaviour. Asia Pac J Mark Logist 23(4): 473-485.

Terblanche NS, Simon E, Taddei JC. 2008. The need for a marketing reform: The wines of the Loire Region. J Int Food \& Agribusiness Mark 20(4): 113-138.

UN Comtrade. 2016. Available at: http://comtrade.un.org/ [2016/5/ 10]. 
Wang H, Zhao XH, Liu J, Fu RP. 2010. Research progress in sustainable development of grape and wine production (In Chinese). Sci Agric Sin 43(15): 3204-3213.

Wang H, Ning XG, Yang P, Li H. 2016. Ancient world, old world and new world of wine (In Chinese). J Northwest A\&F Univer (Social Science Edition) 16(6): 150-153.

Wang SZ, Huang P. 2009. Discussion on grape wine history in China (In Chinese). Liquor-making Sci Tech 2009(11): 136-143.

Willsher K. 2014. China becomes biggest market for red wine, with 1.86 bn bottles sold in 2013. The Guardian. Available from http:// www.theguardian.com/world/2014/jan/29/china-appetite-redwine-market-boom [2016/2/14].

Wine \& Spirit Education Trust (WSET). 2015. Available at http:// www.wsetglobal.com/ [2015/12/16].

Yearbook of China Alcoholic Drinks Industry. 2001. (In Chinese). Publication of China Alcoholic Drinks Industry Association.

Yu Y, Sun HH, Goodman S, Chen SW, Ma HQ. 2009. Chinese choices: a survey of wine consumers in Beijing. Int J Wine Business Res 21(2): 155-168.

Cite this article as: Li Y, Bardají I. 2017. A new wine superpower? An analysis of the Chinese wine industry. Cah. Agric. 26 : 65002. 